\title{
ALTERIDAD Y RECONOCIMIENTO EN LA ONTOLOGÍA MONADOLÓGICA DE LEIBNIZ
}

\section{ALTERITY AND RECOGNITION IN LEIBNIZ'S MONADOLOGICAL ONTOLOGY}

\author{
Roberto CaSALES GaRCíA* \\ UPAEP
}

Resumen: El objetivo principal del presente trabajo de investigación es esclarecer el papel de la alteridad y el reconocimiento en Leibniz, tanto en su lógica de la alteridad y su teoría de la justicia universal, como en su fundamentación ontológica en la naturaleza expresiva y composible de los espíritus. Para lograr este objetivo, he dividido esta investigación en dos partes: en la primera parte busco mostrar en qué medida la alteridad y el reconocimiento son indispensables para comprender la filosofía práctica del hannoveriano; mientras que en la segunda busca analizar la naturaleza expresiva y composible de los espíritus, a fin de articular una incipiente fundamentación ontológica de la moral leibniziana.

Palabras Clave: alteridad, reconocimiento, espíritu, expresividad, composibilidad.

AвsтRACT: The main purpose of the present paper is to clarify the role of alterity and recognition in Leibniz's philosophy, not only in his logic of alterity and his theory of universal justice, but also in the ontological grounding of both notions through the expressive and compossible nature of spirits. In order to achieve this goal, this paper is divided in two parts: in the first part I try to probe in which sense alterity and recognition are essential to understand Leibniz's practical philosophy; while in the second part I analyze the expressive and compossible nature of spirits, in order to articulate an incipient ontological grounding of Leibniz's moral philosophy.

KEYwORDs: alterity, recognition, spirit, expressivity, compossibility.

\footnotetext{
* Universidad Popular Autónoma del Estado de Puebla, 21 Sur \# 1103, Barrio de Santiago, C.P. 72410, Puebla, Pue., México. Mail: roberto.casales@upaep.mx. Director académico de la Facultad de Filosofía, miembro del Sistema Nacional de Investigadores del CONACYT, nivel I.
} 


\section{Introducción}

Incluso cuando el filósofo de Hannover no desarrolla de forma explícita una teoría del reconocimiento, no al menos en el mismo sentido en el que lo hacen Hegel o Fichte, su teoría de la justicia universal contiene ciertos elementos constitutivos que nos permiten articular tanto una lógica de la alteridad, como una incipiente ética del reconocimiento. Me refiero, en particular, a una lógica de la alteridad y una ética del reconocimiento cuyas tesis principales se fundan en la naturaleza expresiva y composible de los espíritus, las cuales impregnan toda su filosofía práctica a través del principio moral de «situarse en el lugar del otro». Teniendo esto en mente, el presente trabajo de investigación tiene por objetivo principal estudiar esta relación concreta entre su filosofía práctica y su metafísica, a fin de esclarecer en qué medida es posible hablar tanto de alteridad como de reconocimiento en Leibniz.

Para lograr esto, he dividido mi texto en dos partes: en la primera parte pretendo esclarecer el papel de la alteridad y el reconocimiento en su filosofía práctica, con la intención de mostrar que ambas son centrales para su teoría de la justicia universal; mientras que en la segunda procuro mostrar la relación entre estas nociones y la constitución ontológica de los espíritus, en particular a través de su naturaleza expresiva y composible.

\section{Alteridad y reconocimiento en la filosofía práctica de Leibniz}

$\mathrm{Al}$ sostener que el verdadero punto de vista de la moral consiste en situarnos en el lugar del otro (Methodus Vitae III, 6-7; Grua, 699-701)1, el filósofo de Hannover no sólo articula un modelo de discernimiento moral distinto a la racionalidad práctica en general, cuyo principio es el de lo mejor ${ }^{2}$, sino que también introduce las nociones de alteridad y reconocimiento como aspectos medulares

\footnotetext{
${ }^{1}$ Todas las obras de Leibniz se citan conforme a los criterios y abreviaturas establecidos por el proyecto "Leibniz en Espańol" (http://leibniz.es/leibniz-en-espanol/), para lo cual he decidido poner, en primer lugar, la referencia a la edición en castellano y, posteriormente, la referencia del texto original al cual alude la correspondiente edición en castellano.

${ }^{2}$ Aunque el hannoveriano sostiene que "la mayor libertad es obligarse por la recta razón a lo mejor" (OFC II, 20; AA II, 1, 186), el principio de conveniencia o de lo mejor se postula como un modelo de racionalidad práctica que subyace a toda acción racional, en cuanto que éste nos determina a actuar siempre en conformidad con el mayor bien aparente (OFC II, 135; AA VI, 4B, 1450; véase también: OFC II, 194; AA, VI, 4B, 1575).
} 
de su filosofía práctica. Para Leibniz, en efecto, este principio es fundamental para el discernimiento moral en cuanto que nos permite, en palabras del hannoveriano, "descubrir consideraciones que sin ello no se nos han ocurrido y que todo lo que encontraríamos ser injusto en el lugar del otro debe contenernos para examinarlo con mayor reflexión. De modo que el sentido del principio es no hagas o no rechaces ligeramente lo que no quisieras que se te hiciese o se te rechazase" (Methodus Vitae III, 6; Grua, 701).

Situarnos en el lugar del otro, así, implica dos cosas: por un lado, reconocerme en el otro, lo cual implica tanto reconocer mi fragilidad y mi necesidad en la del otro ${ }^{3}$, como identificar las consecuencias de mis acciones para discernir si son justas o no; por otro lado, implica reconocer las necesidades del otro en cuanto tal, esto es, reconocerlo como un otro distinto de mí, cuyas necesidades específicas adquieren un carácter normativo en mí. Así, en palabras del hannoveriano, "cada cual debe por mor de la equidad comprender, en cierto modo ponerse en el lugar del otro, y verificar en uno mismo los pensamientos que se haría en la misma situación” (Salas, 498). El 'yo' leibniziano, en este sentido, más que un 'yo' solipsista o un 'yo' radicalmente ensimismado, es un 'yo' que se descubre a sí mismo en la intersubjetividad, de modo que:

Aunque cada uno de nosotros es distinto del otro por razón de la persona, debemos pensar no obstante que ningún hombre puede subsistir por sí solo y considerarnos a nosotros mismos no sólo parte de todo lo creado sino también, en especial, de lo que forma parte de esta tierra, a saber, de la Política, de la sociedad y de la gente a la que estamos vinculados, sea por alojamiento, sea por parentesco u otro tipo de comunidad. Y como hay que anteponer el provecho del todo al de la parte, no será para nosotros más que un placer el servir a todos sin excepción alguna. Además, si lo disponemos

\footnotetext{
${ }^{3}$ A este respecto, resulta interesante la reflexión que hace el hannoveriano en su Méditation sur la notion commune de la justice, a fin de esclarecer en qué medida la justicia no sólo nos demanda evitar el mal a otro, sino también a hacer el bien a los demás: "en general, se te pide, bien hacer algo, bien dejar de hacerlo. Si te niegas a esta petición, habrá motivo de queja, cuando puede afirmarse que pedirías lo mismo si estuvieses en el lugar del otro. Es el principio de equidad o, lo que es lo mismo de igualdad, el que exige que se conceda a otro lo que uno pretendería en el caso de estar en parecidas circunstancias, sin aspirar a un privilegio en contra de la razón, o poder alegar la voluntad propia como razón” (Salas, 93; Mollat, 57). Situarse en el lugar del otro, en este sentido, me permite reconocer lo que exigiría si estuviese en su situación y, en consecuencia, asumirme como alguien necesitado del otro. Se trata, en palabras de Concha Roldán, de un "ponerse reflexivamente en el lugar del otro" que hace "que cada individuo se entienda a sí mismo como una más entre otros" (Roldán 1997, 99).
} 
todo según la inteligencia, nos encontraremos con que eso es también lo que nos conviene a nosotros, pues vemos que, quienes están dispuestos a servir a gusto a los demás, también obtienen de ellos a su vez grandes amistades y servicios, incluso de quienes no estuvieron al servicio de uno. El trabajo que nos tomamos al servicio de los demás, es mucho menor que las ventajas que de su amistad tenemos. (Methodus Vitae III, 175; GP VII, 93).

La lógica de la alteridad que subyace a este principio moral leibniziano, acorde a la cita anterior, transita de un sentido meramente restrictivo -el 'no hagas' o 'no rechaces'-, a una caracterización que asume tanto esta negatividad, como una dimensión propositiva que nos incita a la acción ${ }^{4}$ : situarse en el lugar del otro no sólo implica limitar mis acciones o evitar el mal, sino también buscar el bien ajeno, hacer el bien. En otras palabras, no basta con no hacer aquello que no quiero que me hagan, sino que también debo promover, en la medida de mis posibilidades, el bien y la felicidad ajena. Se trata, pues, de un principio hermenéutico que me permite reconocer tanto las consecuencias de mis propios actos, como las necesidades del otro en cuanto tal, tema fundamental para comprender su teoría de la justicia universal. En opinión de Leibniz, en efecto, es posible afirmar que "la justicia, al menos entre los hombres, consiste en la constante voluntad de actuar de modo que, en lo posible, no pueda haber queja de nosotros en las situaciones en que nosotros podríamos quejarnos del otro... así lo que es justo es conforme a la caridad del sabio" (Salas, 94; Mollat, 58).

Esta última definición de lo justo presupone fundamentalmente dos cosas: por un lado, que el justo es aquel que posee el hábito de amar a los otros (Cf. Salas, 106; Mollat, 36. Véase también: Guillén, 80; AA VI, 1, 465), en cuanto que la caridad constituye una benevolencia general que nos mueve a buscar el bien y la felicidad ajena de forma desinteresada o incondicional, es decir, sin esperar algún otro bien a cambio (Cf. Salas, 107; Mollat, 36-37); por otro lado, que esta conmoción o tendencia a buscar el bien y la felicidad ajena no es arbitraria, sino que presupone actuar en conformidad con la razón, de modo que,

\footnotetext{
${ }^{4} \mathrm{Al}$ admitir tanto una lectura restrictiva, como una lectura propositiva de la regla de oro, según Gregory Brown (2011, 234), el filósofo de Hannover opone su teoría de la justicia universal a la propuesta específica de Hobbes, quien sólo admite una lectura restrictiva de este principio. Para Leibniz, sin embargo, la regla de oro nos ordena taxativamente hacer el bien: "se me concederá entonces que es preciso evitar el mal a otro si esto puede hacerse cómodamente; pero quizá no se admita que la justicia ordena taxativamente hace el bien a los demás. A propósito de esto, yo pregunto si al menos no se está obligado a aliviar sus males" (Salas, 92; Mollat, 55).
} 
en palabras de Leibniz, "no se haga daño sin necesidad a nadie y se haga [antes] bien <en cuanto pueda uno; más, sobre todo>, allá donde esté mejor empleado, [y perfecto y más amable]" (Methodus Vitae III, 109; Grua, 583). Situarse en el lugar del otro, en palabras de Concha Roldán, es un principio que nos obliga "a superar el egoísmo individual, sustituyéndolo por el amor al prójimo que nos permite colocarnos «en el lugar del otro», obteniendo felicidad de su perfección" (Roldán 2017, 119). De ahí que el hannoveriano sostenga que la máxima regla del derecho, siguiendo esta lógica de la alteridad, "consiste en encaminar todos nuestros actos a la consecución del bien general” (Salas, 112; Mollat, 8-9) ${ }^{5}$.

Cuando hablamos de la teoría leibniziana de la justicia universal, en este sentido, no sólo entendemos la justicia en términos de un ius strictum, principio que nos prescribe "no hacer daño a otra persona" (Salas, 93; Mollat, 57), sino también como una benevolencia "activa”, expresión de Patrick Riley (1996, 18), la cual nos demanda "que se haga el bien cuando es oportuno", principio de equidad que nos mueve a "dar a cada uno lo que le corresponde" (Salas, 93; Mollat, 57). Al comprender ambos niveles, sin embargo, la teoría leibniziana de la justicia universal se sitúa dentro de un orden superior que nos prescribe amar a todos según la razón, principio que, en el caso específico de los espíritus creados, debe interpretarse de la siguiente forma:

Y no entiendo esto como si fuera necesario que el hombre justo o bueno se distinga en el conocimiento de las cosas y conozca las primeras causas de lo bueno y lo justo, sino en el sentido en que las cosas que conciernen a la caridad, las hará como las haría y prescribiría hacer el sabio. Por consiguiente, el justo acostumbrará actuar del modo más racional, o, al menos -lo que es suficiente-, estará dispuesto a imitar al sabio. Y, como las otras virtudes consisten en moderar las otras pasiones, así hay que pensar que la justicia se ocupa en dirigir la voluntad del hombre hacia el bien del prójimo, y trata de que todos intentemos ser útiles y no perjudiquemos a nadie. (Salas, 105; Mollat, 35).

Las nociones de alteridad y reconocimiento, a pesar de que juegan un papel central en la filosofía práctica del hannoveriano, resultan un tanto conflictivas al momento de articularlas con su ontología monadológica, particularmente si se concibe a las mónadas como entidades cerradas y carentes de relaciones. Esta

\footnotetext{
${ }^{5}$ Algo semejante sostiene cuando define esta regla suprema del derecho como el deber de hacer lo que es útil a la comunidad (Salas, 137; Mollat, 85).
} 
lectura de su ontología monadológica, tal y como trataré de mostrar a continuación, olvida por completo que las mónadas leibnizianas son entidades relacionales, en palabras de Leibniz: "las mónadas no existen solitarias. Son mónadas, no anacoretas" (OFC II, 296; Grua, 395). Así, a pesar de que "las mónadas no tienen en absoluto ventanas" (OFC II, 328; GP VI, 607), como sostiene el hannoveriano en el $\$ 7$ de su Monadologie, esto no significa que sean entidades aisladas, ni que carezcan por ello de relaciones.

\section{Expresividad y composibilidad de los espíritus}

La naturaleza relacional de las mónadas, si mi lectura del hannoveriano es correcta, alude fundamentalmente a dos elementos clave de su ontología: por un lado, a la naturaleza expresiva o representativa de toda substancia simple, la cual se articula al interior de su teoría de la percepción y la apetición; por otro lado, a su composibilidad constitutiva, en virtud de la cual se da cabida tanto a su sistema de la armonía preestablecida, como a la elección divina del mejor de los mundos posibles. A través de lo primero se afirma que toda mónada o sustancia simple "es como un mundo entero y como un espejo de Dios o bien de todo el universo, que cada una expresa a su manera, de modo análogo a como una misma ciudad es diversamente representada según las diferentes situaciones de quien la contempla” (OFC II, 170; AA, VI, 4B, 1542). De ahí que las mónadas, en cuanto que se expresan mutuamente, se limiten y acomoden entre sí, dando por resultado un universo armónico, tal y como se aprecia en el $\$ 56$ de su Monadologie: "esta ligazón o acodamiento de todas las cosas creadas a cada una y de cada una a todas las demás, hace que cada sustancia simple tenga relaciones que expresan a todas las demás, y que por consiguiente sea un espejo vivo y perpetuo del universo" (OFC II, 336; GP, VI, 616).

En términos generales, se dice que "una cosa expresa a otra (según mis términos) cuando hay una relación constante y reglada entre lo que se puede decir de la una y de la otra" (OFC XIV, 126; Finster 310), de modo que, entre el significado y el significante, "hay respectos (habitudines) que responden a los respectos de la cosa que va a expresarse" (Gredos, 25; GP, VII, 263; véase también: Beleval 1986, 46). Lo cual no implica que esta correspondencia establezca una relación de igualdad entre la expresión y lo expresado, sino, a lo mucho, una relación analógica, cuya aplicación a su ontología monadológica implica, en palabras de Bernardino Orio de Miguel, que "cada substancia responde a todas las demás desde sus propios requisitos", de modo que cada una "auto-descubre, 
auto-manifiesta, auto-expresa..., sus internas propiedades ante el reflejo o imagen que las demás dejan en ella” (Orio de Miguel 2011, 126).

A partir de lo cual se sigue que el tipo de expresión al que se alude en el caso específico de las mónadas, difiere de otros tipos de expresión, como ocurre con la geometría proyectiva, puesto que, si bien es cierto que cada una de las cónicas mantiene una relación de correspondencia entre sí, esta relación mantiene un carácter biunívoco. La naturaleza expresiva de las mónadas, sin embargo, se entiende no como una relación biunívoca, i.e., como una relación uno a uno ${ }^{6}$, sino más bien como una relación armónica inter-especular en la que cada mónada se relaciona con la totalidad de individuos que componen el cosmos. De este modo, como señala Laura Herrera, las mónadas "no sólo expresan las sustancias, sino que lo hacen acomodándose unas a otras" (Herrera 2012, 268). Para Leibniz, en efecto, "cada sustancia individual de este universo expresa en su noción el universo del que forma parte", de manera que la naturaleza individual de cada una "contiene resoluciones para todo el resto", en cuanto que ésta consiste en "tener una noción completa, de la que se puede deducir todo lo que se le pueda atribuir e incluso todo el Universo, por la conexión de las cosas" (OFC XIV, 39; Finster, 88). De ahí que la naturaleza expresiva de las mónadas sirva de fundamento ontológico tanto del perspectivismo leibniziano, como para entender su naturaleza relacional, tal y como se observa en su correspondencia con De Volder:

En mi opinión, ninguna cosa hay en todo el universo de las criaturas que no necesite del concepto de cualquier otra de entre la universalidad de las cosas para la formación de su perfecto concepto, puesto que cada una influye en cualquier otra de manera que, si aquélla desapareciera o la imagináramos distinta, todas las cosas en el mundo serían distintas de como ahora son. (OFC XVI B, 1165; GP II, 226).

Aunque la teoría leibniziana de la expresión se encuentra en el fondo de una amplia variedad de temas a lo largo de su $\mathrm{obra}^{7}$, su aplicación concreta a su teoría de la percepción y, por ende, a su metafísica, nos permite afirmar, con Félix

\footnotetext{
${ }^{6}$ Tal y como señala Alejandro Herrera, una de las limitaciones propias de la metáfora o símil del 'espejo' radica justo en que ésta "insinúa que hay una correspondencia biunívoca entre representante y representado, lo cual no es exigido por la relación de representación” (Herrera 1993,96$)$.

${ }^{7}$ Un estudio más amplio de ésta se encuentra en la obra de Valérie Debuiche, véase, por ejemplo: Debuiche 2009, 88-117.
} 
Duque, que toda mónada "es cosa en sí a fuerza de ser para Otro: el mundo que ella expresa con limitados grados de claridad-razón, y de ser por Otro" (Duque 1994, 299). En el caso específico de los espíritus, esto significa que no sólo son imágenes vivas del universo, sino también imágenes de la divinidad (OFC II, 340; GP VI, 621), estatuto ontológico que resignifica su relación tanto con Dios, como con la comunidad de espíritus que habitan el mundo. Tesis que el hannoveriano sostiene en el siguiente pasaje, el cual me permito citar en extenso:

En efecto, los espíritus son las sustancias más perfeccionables y sus perfecciones poseen de particular que entre sí se estorban lo mínimo o, mejor dicho, que se ayudan mutuamente, pues solamente los más virtuosos podrán ser los amigos más perfectos; de ahí se sigue de manera manifiesta que Dios, que busca siempre la máxima perfección en general, tendrá el mayor cuidado de los espíritus, y les proporcionará no sólo en general, sino incluso a cada uno en particular, la mayor perfección que permita la armonía universal. Puede incluso decirse que Dios, en tanto que es un espíritu, es el origen de las existencias, pues, de otro modo, si le faltara voluntad para elegir lo mejor, no existiría razón alguna para que un posible existiera con preferencia a otros. Así, la cualidad que posee Dios de ser Él mismo espíritu precede a todas las demás consideraciones que se puede tener al respecto de las criaturas; sólo los espíritus son hechos a su imagen, son como de su linaje o como hijos de la casa, ya que solamente ellos pueden servirle libremente y actuar con conocimiento a imitación de la naturaleza divina. Un solo espíritu vale por todo el mundo, pues no sólo lo expresa, sino que también lo conoce y se gobierna a sí mismo a la manera de Dios. De modo tal que parece que, aunque cualquier sustancia expresa el universo entero, sin embargo las demás sustancias expresan más bien el mundo que a Dios y, en cambio, los espíritus expresan más bien a Dios que al mundo. (OFC II, 202; AA, VI, 4B, 1586-1587).

La diferencia entre la naturaleza expresiva de las mónadas en general y la de los espíritus, así, radica en que las primeras se limitan a expresarse mutuamente desde su propia perspectiva, mientras que los espíritus, al ser imágenes de la divinidad, son capaces de mirarse a sí mismas en su mutua relación con el mundo, de modo que, en palabras del hannoveriano, "la diferencia es tan grande como la que existe entre el espejo y quien lo mira” (OFC II, 201; AA, VI, 4B, 1586). Mientras que las mónadas en general son concebidas como meros espejos cuya actividad es reflejarse y limitarse mutuamente, restringiendo su acción al lugar en el que se encuentran situados, los espíritus poseen la capacidad de interactuar con el mundo desde distintas perspectivas. Los espíritus, en efecto, no sólo reflejan el 
cosmos, sino que, al ser capaces de reconocerse a sí mismos en los otros, logran orientar su existencia para situarse en el mundo ${ }^{8}$. De ahí que, en palabras de Leibniz, "el espíritu deb(a) figurar siempre en este universo del modo más apropiado para contribuir a la perfección de la sociedad de todos los espíritus que constituye su unión moral en la Ciudad de Dios" (GP IV, 486. El paréntesis es mío).

$\mathrm{Al}$ sostener que los espíritus poseen esta peculiar naturaleza expresiva que les permite interactuar con el mundo, en cuanto que son capaces de imitar a la divinidad y de contribuir a la consolidación de la Ciudad de Dios, se afirma también que poseen el deber de comprenderse a sí mismos como seres relacionales, cuyo único bien real es el bien común (Casales 2018). Esto último, sin embargo, presupone que las mónadas no sólo tienen una naturaleza relacional, sino también un ser composible, en virtud del cual es imposible que un espíritu se comprenda a sí mismas sin, por ello, incluir dentro de su noción a la totalidad de seres que componen el cosmos. La razón última de mi existir, acorde con la propuesta leibniziana, radica en mi ser composible, en la medida en que "no pueden existir todas las cosas posibles" (OFC II, 70; AA VI, 3, 473), sino tan sólo aquellas que encierran un mayor grado de perfección o esencia: "sean dos posibles, $A$ y $B$, de los cuales es necesario que deba existir uno u otro; supuesto que haya más perfección en $A$ que en $B$, entonces seguramente puede darse razón de por qué existe $A$ más bien que $B$ ” (OFC II, 129; AA VI, 4B, 1446).

La composibilidad, en este sentido, tiene que ver tanto con el grado de perfección o realidad que contienen las esencias posibles, como con la conexión intrínseca que existe entre los diversos seres que componen una misma serie o mundo posible. Así, aunque existe una amplia variedad de esencias y mundos posibles, en cuanto que se llama posible a todo aquello "que se pued(e) suponer o pensar sin contradicción” (OFC II, 117; AA VI, 4B, 1352. El paréntesis es mío), no todos los posibles son compatibles entre sí y, por tanto, no todos son

\footnotetext{
${ }^{8}$ No en vano, el hannoveriano sostiene que la raíz de la libertad consiste en nuestro ser imágenes de la divinidad (cf. OFC II, 137; AA VI, 4B, 1452), en cuanto que "el espíritu no tiene solamente una percepción de las obras de Dios, sino que es también capaz de producir algo que se parece a ellas, aunque en pequeño. Pues, por no decir nada de las maravillas de los sueños, en los que inventamos sin esfuerzo (pero también sin tener voluntad de ello) cosas en las que, cuando se está despierto, sería menester pensar mucho tiempo para encontrarlas, nuestra alma es arquitectónica también en las acciones voluntarias y, al descubrir las ciencias según las cuales Dios ha regulado las cosas (pondere, mensura, numero, etc.), imita en su circunscripción, en el pequeño mundo en el que es permitido desempeñarse, lo que Dios hace en el grande" (OFC II, p. 350; Robinet I, 55-57).
} 
susceptibles de entrar en composición en la misma serie o mundo posible. De manera que, tal y como sostiene Agustín Echavarría, sólo son composibles "aquellas cosas que no implican contradicción al ser pensadas como pertenecientes a una misma serie" (Echavarría 2011, 180). Esto nos permite suponer que una serie o mundo posible es más perfecta en la medida en que encierra un mayor grado de composibilidad, esto es, en la medida en que admite una mayor cantidad de seres composibles: "entre las infinitas combinaciones de los posibles y las series posibles existe aquélla por media de la cual llega a la existencia la mayor cantidad de esencia, o sea, de posibilidad" (OFC II, 279; GP, VII, 303. Véase también: OFC II, 302; Couturat, 534). En resumen:

Aceptemos que hay seres posibles, A, B, C, D, E, F, G, igual de perfectos y pretendiendo todos existir, siendo incompatibles $\mathrm{A}$ con $\mathrm{B}, \mathrm{B}$ con $\mathrm{D}, \mathrm{D}$ con $\mathrm{G}, \mathrm{G}$ con $\mathrm{C}, \mathrm{C}$ con $\mathrm{F}$ y $\mathrm{F}$ con $\mathrm{E}$. Digo entonces que dos podrán existir a la vez de quince maneras, $\mathrm{AC}, \mathrm{AD}, \mathrm{AF}, \mathrm{AG}, \mathrm{BC}, \mathrm{BE}, \mathrm{BF}, \mathrm{BG}, \mathrm{CD}, \mathrm{CE}, \mathrm{DE}$, $\mathrm{DF}, \mathrm{EG}, \mathrm{FG}$, o bien podrán existir tres a la vez de las siguientes maneras, ACD, ACE, ADE, AEG, AEF, BCE, BEG y BFG, o bien cuatro a la vez de una sola manera, $\mathrm{ACDE}$, la cual será elegida entre todas las demás, porque con ella se obtiene lo más que se puede, y por tanto esto cuatro, A, C, D y E existirán con preferencia a los otros tres, B, F, G, los cuales quedarían excluidos, debido a que tomando uno cualquiera de ellos no se logra obtener cuatro a la vez. (Gredos, 644; Grua, 286).

Dada esta caracterización de las mónadas leibnizianas como entidades relacionales, en especial en su aplicación al caso específico de las sustancias racionales, se sigue que los espíritus, por más autosuficientes que sean, no pueden comprenderse a sí mismos como entidades ajenas al mundo (Casales 2015, 213). Los espíritus, en efecto, no son entidades aisladas o carentes de relaciones, sino entidades cuya naturaleza expresiva y composible los vincula con la totalidad de seres que componen el mundo, de modo que no pueden ni deben prescindir de su relación con los demás. 


\section{Conclusiones}

A pesar de que las lecturas estándar de Leibniz tienden a escindir su metafísica y su filosofía práctica, en el presente trabajo de investigación he mostrado un posible punto de encuentro entre ambos aspectos de su filosofía, el cual, a su vez, sirve para esclarecer el papel que juega la alteridad y el reconocimiento al interior de su propuesta. Esto significa que no podemos prescindir de ellas ni en su filosofía práctica ni en su metafísica, ya sea porque la primera se reduciría a un mero cálculo ético individualista, o sea porque la segunda, por más fuerza argumentativa que poseyera, sería radicalmente ajena a la realidad. Cuando hablamos de alteridad y reconocimiento en Leibniz, en efecto, no sólo aludimos a aquello que tienen en común su filosofía práctica con su metafísica, sino que también aludimos a una fundamentación ontológica de la moral. Así, a modo de conclusión, podemos sostener que sólo es posible situarse en el lugar del otro, tal y como reza el principio moral leibniziano, en la medida en que poseemos una naturaleza relacional que nos enlaza, tanto a nosotros, como a nuestra felicidad, sistemática a los otros.

\section{Agradecimientos}

Quiero agradecer explícitamente a los evaluadores, en la medida en que sus comentarios ayudaron a mejorar en buena medida el contenido de este artículo. Agradezco también al Dr. Alejandro Herrera Ibáñez, por su acompañamiento y compromiso en la búsqueda sincera de la verdad, en particular en el estudio de un autor tan complejo como Leibniz. 


\section{Bibliografía}

Beleval, Y. (1986). "La place de la Nova Methodus dans le système leibnizien". En: Studia Leibnitiana - Sonderheft, 14, pp. 38-47.

Brown, G. (2011). “Leibniz's Moral Philosophy”. En: Look, B. (ed.). The Continuum Companion to Leibniz. Londres: Continuum.

Casales, R. (2018). Justicia, amor e identidad en la ontología monadológica de Leibniz. Nova Leibniz 9, Granada: Comares.

- (2015). "El conflicto entre la espontaneidad y comunicación entre las sustancias: un tema clave para comprender el paso de la ontología leibniziana a su filosofía práctica”. En: Casales, R. y Solís, R. (comp.). Libertad y necesidad en Leibniz. Ensayos sobre el laberinto leibniziano de la libertad. Puebla: UPAEP, pp. 203-218.

Debuiche, V. (2009). "La notion d'expression et ses origines mathématiques”. En: Studia Leibnitiana, Bd. 41, H. 1, pp. 88-117.

Duque, F. (1994). "La fuga del universo”. En: Racionero, Q. y Roldán, C. (coord.). G. W. Leibniz. Analogía y expresión. Madrid: Editorial Complutense, pp. 289-305.

Echavarría, A. (2011). Metafísica leibniziana de la permisión del mal. Pamplona: EUNSA.

Herrera, A. (1993). “Leibniz y su visión ontológica de la percepción”. En: Benítez, L. y Robles, J.A. (comp.). Percepción: colores. México: UNAM, pp. 91-100.

Herrera, L.E. (2012). "La expresión como función. Sobre el carácter funcional del concepto de expresión en G.W. Leibniz”. En: Revista de Filosofía de la Universidad de Costa Rica, LI (129-131), pp. 263-271.

Leibniz, G.W. (1965). Die Philosophischen Schriften. Herausgegeben von Gerhardt, C.I., Hildesheim.

- (2001). Escritos de filosofía politica y jurídica. Ed. de Salas, J., Madrid: Biblioteca Nueva.

- (1997). G. W. Leibniz. Der Briefwechsel mit Antoine Arnauld. Ed. de Finster, R. Felix Meiner Verlag, Hamburg.

- (2010). G. W. Leibniz. Obras filosóficas y cientificas. 2. Metafísica. Ed. González, A.L., Granada: Comares.

- (2007). G. W. Leibniz. Obras filosóficas y cientificas. 14. Correspondencia I. Ed. de Nicolás, J.A., Granada: Comares.

- (2011). Gottfried Wilhelm Leibniz. Ed. de Echeverría, J., Madrid: Gredos. 
- (1991). Los elementos del Derecho natural. Trad. Guillén Vera, T., Madrid: Tecnos.

- (2015). Methodus Vitae (Escritos de Leibniz). Vol. III: Ética o politica. Trad. Andreu, A., Madrid: Plaza y Valdés.

- (1893). Mitteilungen aus Leibnizens ungedrucken Schriften. Von Mollat, G. Leipzig.

- (1961). Opuscules et fragmentes inédits de Leibniz. Extraits des manuscrits de la Bibliothèque royale de Hannovre. Par Couturat, L. Hildesheim.

- (1954). Principes de la nature et de la grâce fondés en raison. Principes de la philosophie ou monadologie. Publiés intégralement d'après des lettres inédites par Robinet, A., Paris.

- (1923). Sämtliche Schriften und Briefe. Von der Deutschen Akademie der Wissenschaften zu Berlin, Darmstadt (1923 y ss.), Leipzig (1938 y ss.), Berlín (1950 y ss.).

- (1948). Textes inédits d'après les manuscrites de la bibliothèque provinciale de Hannovre. Publiés et annotés par Grua, G. Paris.

Orio de Miguel, B. (2011). Leibniz. Crítica de la razón simbólica. Nova Leibniz 1, Granada: Comares.

Riley, P. (1996). Leibniz Universal Jurisprudence. Justice as the Charity of the Wise. Cambridge, Massachussetts: Harvard University Press.

RoldÁn, C. (2017). "Mejorando el mejor de los mundos posibles: ética y política en Leibniz". En: Casales, R. y Castro, M. (comps.). La modernidad en perspectiva. A trescientos años del fallecimiento de Leibniz. Granada: Comares, pp. 115-129.

- (1997). "Theoria cum praxi: la vuelta a la complejidad. (Apuntes para una filosofía práctica desde el perspectivismo leibniziano)”. En: Isegoría, 17, pp. 85-105.

Recibido: 30/10/2018

Aceptado: 13/03/2019

Este trabajo se encuentra bajo una licencia de Creative Commons Reconocimiento-

NoComercial-SinObraDerivada 4.0

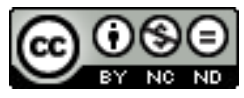


